\title{
Eating disorders and disordered eating behaviors in males: a challenging topic
}

\author{
Emilia Manzato $^{1} \mathbb{D}$
}

Received: 24 April 2019 / Accepted: 8 May 2019 / Published online: 18 May 2019

(c) Springer Nature Switzerland AG 2019

A brief overview of some challenges still present in the area Eating Disorders in males may introduce the Topical Collection devoted to this field.

Eating disorders (EDs) have long been considered female gender-bound disorders. This view, persistent over time, has led to a significant underestimation of EDs in males. As a result, they have not been adequately studied.

The first description of a case of "phthisis nervosa" in a man, with starvation and undernutrition related to a psychiatric disorder, is due to Sir Richard Morton (1637-1698), an English physician who, in 1689, described the 16-year-old son of a church minister suffering from "nervous consumption" [1].

Since then, however, research studies have focused mainly on the female gender, and the various editions of the "Diagnostic and Statistical Manual of Mental Disorders" (DSM) have followed this perspective, making the study of male EDs more difficult.

In DSM-IV, diagnostic criteria were mostly tailored for the female gender. The introduction of the amenorrhea criterion has made it difficult to find a corresponding criterion in males (i.e., a low level of testosterone or decrease in the sexual drive) and downgraded many cases of male Anorexia Nervosa (AN) under the umbrella term Eating Disorders not otherwise specified (EDNOS) [2].

A substantial revision has resulted in more sex-neutral and more inclusive diagnostic criteria in DSM-5. In particular, the amenorrhea criterion has been removed, and the evaluation of significantly low body weight has become more flexible and is left to the appraisal of the clinician.

This article is part of topical collection on Males and eating and weight disorders.

Emilia Manzato

emilia.manzato@gmail.com

1 University of Ferrara, Ferrara, Italy
However, it remains uncertain the diagnosis of some atypical AN cases (women and men), normal-weight or overweight with severe anorexic features [3-5].

Many other difficulties persist in the study of male EDs leading to conflicting results or opinions. A short list of those is as follows:

- The small clinical samples and their heterogeneity [6].

- In the general population studies, instruments and designs are really different and poorly comparable [7].

- The frequent use of diagnostic tools (e.g., tests, questionnaires) tailored for females.

- The accurate prevalence and incidence of EDs in males are still questionable.

- The diagnostic delay linked to the stereotype of the EDs as a female disorder that has always caused difficulty in identifying male EDs.

- The inadequate training of the therapists and discomfort of male patients to turn to services oriented mainly toward the women $[8,9]$.

- Body Mass Index (BMI) as the primary diagnostic tool in AN to assess the severity of the clinical picture: in fact, $\mathrm{BMI}$ has revealed its great inadequacy in male $\mathrm{AN}$, and this has stimulated the study of broader reference scores.

- The muscle ideal and the thin ideal sometimes coexist and take turns.

- Not only anorexia nervosa, bulimia nervosa, and binge eating disorder but also many other disordered eating behaviors (e.g., purging disorder, orthorexia nervosa, drunkorexia, food addiction) should be explored in men [10-13].

Burdened by these limitations, research studies have produced results that are insufficient and not consistent. They have conditioned the vision of EDs in males over time. These problems represent a powerful incentive for new and different studies [14-16]. 


\section{Compliance with ethical standards}

Conflict of interest The authors declare that there is no conflict of interest.

\section{References}

1. Morton R (1689) Phthisiologia seu Exercitationes de Phthisi. Tribus Libris Comprehensae London Smith, London

2. Murray SB, Nagata JM, Griffiths S, Calzo JP, Brown TA, Mitchison D, Blashill AJ, Mond JM (2017) The enigma of male eating disorders: a critical review and synthesis. Clin Psychol Rev 57:1-11.https://doi.org/10.1016/j.cpr.2017.08.001

3. Mustelin L, Silen Y, Raevuori A et al (2016) The DSM-5 diagnostic criteria for anorexia nervosa may change its population prevalence and prognostic value. J Psychiatry Res 77:85-91. https ://doi.org/10.1016/j.jpsychires.2016.03.003

4. Murray SB, Griffiths S, Mitchison D, Mond JM (2017) The transition from thinness-oriented to muscularity-oriented disordered eating in adolescent males: a clinical observation. J Adolesc Health 60(3):353-355. https://doi.org/10.1016/j.jadohealth .2016 .10 .014

5. Gualandi M, Simoni M, Manzato E, Scanell G (2016) Reassessment of patients with eating disorders after moving from DSM-IV towards DSM-5: a retrospective study in a clinical sample. Eat Weight Disord. https://doi.org/10.1007/s40519-016-0314-4

6. Strobel C, Quadflieg N et al (2018) Short- and long-term outcome of males treated for anorexia nervosa: a review of the literature. Eat Weight Disord 23(5):541-552. https://doi.org/10.1007/s4051 9-018-0538-6

7. Anu Raevuori A, Keski Rahkonen A, Hoek HW (2014) A review in males of eating disorders. Curr Opin Psychiatry 27(6):426-430. https://doi.org/10.1097/yco.0000000000000113

8. MacLean A, Sweeting H et al (2015) "It's not healthy and it's decidedly not masculine": a media analysis of UK newspaper representations of eating disorders in males. BMJ Open. https://doi. org/10.1136/bmjopen-2014-007468
9. Kinnaird E, Norton C, Tchanturia C (2018) Clinicians' views on treatment adaptations for men with eating disorders: a qualitative study. BMJ Open. https://doi.org/10.1136/bmjopen-2018-021934

10. Wang SB, Borders A (2017) Rumination mediates the associations between sexual minority stressors and disordered eating, particularly for men. Eat Weight Disord 22(4):699-706. https:// doi.org/10.1007/s40519-016-0350-0

11. Grammatikopoulou MG, Gkiouras K et al (2018) Food addiction, orthorexia, and food-related stress among dietetics students. Eat Weight Disord 23(4):459-467. https://doi.org/10.1007/s4051 9-018-0514-1

12. Gorrell S, Walker DC, Anderson DA, Boswell JF (2018) Gender differences in relations between alcohol-related compensatory behavior and eating pathology. EatWeight Disord. https://doi. org/10.1007/s40519-018-0545-7

13. Canan F, Karaca S, Sogucak S, Gecici O, Kuloglu M (2017) Eating disorders and food addiction in men with heroin use disorder: a controlled study. Eat Weight Disord 22(2):249-257. https://doi. org/10.1007/s40519-017-0378-9

14. de Leon-Vazquez CD, Villalobos-Hernandez A, Rivera-Marquez JA, Unikel-Santoncini C (2018) Effect of parental criticism on disordered eating behaviors in male and female university students in Mexico City. Eat Weight Disord. https://doi.org/10.1007/s4051 9-018-0564-4

15. Foye U, Hazlett DE, Irving P (2019) Exploring the role of emotional intelligence on disorder eating psychopathology. Eat Weight Disord 24(2):299-306. https://doi.org/10.1007/s4051 9-018-0629-4

16. Valente S, Di Girolamo G, Forlani M, Biondini A, Scudellari P, De Ronchi D, Atti AR (2017) Sex-specific issues in eating disorders: a clinical and psychopathological investigation. Eat Weight Disord 22(4):707-715. https://doi.org/10.1007/s4051 9-017-0432-7

Publisher's Note Springer Nature remains neutral with regard to jurisdictional claims in published maps and institutional affiliations. 